MACHADO, Maria das Dores. Política e Religião: a participação dos evangélicos nas eleições. Rio de Janeiro: FGV, 2006, 180pp.

\title{
Um olhar sobre o Assistencialismo E o Corporativismo NA POLÍTICA EVANGÉLICA
}

\section{Suene dos Santos de Almeida}

Em Política e Religião, Maria das Dores Machado analisa a importância da dimensão religiosa nos processos eleitorais de 2000 e 2002 no município do Rio de Janeiro, o qual ocupa o quarto lugar em população evangélica no ranking das unidades federativas do Brasil e tem se destacado "como cenário de disputas entre grupos religiosos que enveredam pelo espaço da política com o objetivo de ampliar a influência de suas respectivas denominações na esfera pública"(:11). O livro é resultado de dois projetos de pesquisa desenvolvidos pela autora na Escola de Serviço Social da UFRJ - "Pentecostais e Neopentecostais na disputa política do Rio de Janeiro: interesses materiais e ideais em jogo", entre agosto de 2000 e julho de 2002, e "Religião e Cultura Política: a participação dos evangélicos nas eleições de 2002 e o clientelismo político no Rio de Janeiro", entre agosto de 2002 e julho de 2005 - e trata das competições eleitorais no município do Rio em 2000 e da disputa pela presidência, pelo governo estadual, e pelo legislativo regional e federal em 2002, através da identificação dos atores religiosos em disputas eleitorais, suas comunidades confessionais, agremiações partidárias e agenda política, e de uma análise da atuação dos parlamentares evangélicos durante o primeiro ano de seu mandato.

A autora organiza os principais temas abordados em sua pesquisa em torno da hipótese central de que o engajamento em comunidades religiosas por parte dos candidatos evangélicos analisados favorece, em certa medida, o surgimento de novas lideranças políticas, e que, atrelado a esse processo, verifica-se também o acirramento do corporativismo e do clientelismo na política nacional. A partir desta hipótese, procura demonstrar que, "embora se perceba uma tendência crescente de utilização do engajamento em atividades assistencialistas como recurso eleitoral, a pertença religiosa foi o principal recurso acionado pelos atores políticos desse segmento religioso no pleito em questão"(:13). E com este intento privilegia, de modo perspicaz, a análise da participação feminina no grupo de políticos evangélicos do Estado, que se revela de suma importância para a compreensão dos processos de formação das lideranças desse segmento religioso e de ampliação de seu poder político, bem como de suas respectivas denominações. A participação de mulheres evangélicas na política 
institucional, suas peculiaridades e sua relação com a participação feminina na política brasileira atualmente são apresentadas aqui como uma alternativa interessante para a já tradicional discussão sobre a relação entre religião e política na sociedade brasileira contemporânea.

O debate sobre a presença cada vez maior do segmento evangélico no universo da política nacional se articula neste texto com as investigações sociológicas empreendidas na década de 80 , que identificavam a ampliação da participação evangélica na política, mais particularmente pentecostal, como um retrocesso no processo de secularização da esfera política. Machado recupera elementos deste debate que apontavam o fisiologismo, o conservadorismo e o corporativismo como características marcantes na atuação destes atores, e que contestavam as teses que defendiam o apoliticismo dos pentecostais, para, em seguida, se inserir no campo da análise atual sobre o tema. As reflexões mais atuais, além de terem superado as discussões sobre o suposto apoliticismo dos pentecostais - hipótese já descartada -, apontam para uma perspectiva de análise que leva em conta a diversidade de doutrinas e práticas religiosas entre os evangélicos, o que se refletiria numa heterogeneidade de interesses e objetivos no interior deste grupo no que diz respeito à sua atuação na arena política nos diferentes contextos históricos. Outra tendência atual de análise é a ampliação de seu escopo tanto no que diz respeito ao comportamento eleitoral dos fiéis, quanto no que fiz respeito à atuação política dos dirigentes.

No entanto, outras perspectivas se apresentam juntamente às tendências mais gerais apresentadas anteriormente. Machado ressalta que, embora a discussão atual sobre a presença das religiões na esfera pública brasileira se organize em torno de dois eixos - o princípio legal da separação entre o Estado e a Igreja e a tese da privatização moral da religião - autores como Casanova (1999) e Paula Montero (2002) defendem ser fundamental reconhecer a distinção entre estes dois processos, ainda que sejam conexos. Nesta perspectiva, a presença da religião na esfera pública pode se configurar com o objetivo de proteger não só a liberdade religiosa, "mas todas as liberdades e direitos modernos e o próprio direito de existência de uma sociedade civil e democrática. E nesse caso a religião estaria ajudando a constituir e/ou manter a ordem social e política liberal"(:20). Outra função que a religião pode adquirir no contexto moderno é a de "questionar a pretensão de autonomia absoluta das esferas seculares de se organizar de acordo com princípios de diferenciação, desconsiderando valores éticos e morais"(:20). Todavia, é de suma importância, segundo a autora, ir além destas proposições e questionar o valor analítico do próprio modelo liberal de separação do Estado em relação à religião. Tomando como referência a tese de Guimbelli (2002), Machado se propõe a pensar o modelo liberal de separação das esferas como uma das modalidades possíveis de relação do Estado com as religiões, expressas de formas variadas e controversas no decorrer da história e de acordo com cada organização social. 
Essa é uma idéia central em sua análise, pois direciona sua atenção aos processos que envolvem a relação entre o campo da religião e o campo da política no contexto atual, tanto em seu caráter estrutural quanto conjuntural. A crescente inserção dos evangélicos, em especial do segmento pentecostal, na política nos remete, sem dúvida, à análise da perda de influência da Igreja Católica nas instituições supostamente seculares de nossa sociedade e em nossa organização social de modo geral. Nos remete também à modalidade de atuação que configura inicialmente a participação dos chamados "protestantes históricos" na política nacional. Mais do que isso, e como a autora propõe, pensar o campo da política brasileira contemporânea, que está, como sempre esteve, impregnado da presença religiosa, exige considerar nossa herança cultural, fundamentada no catolicismo, e vislumbrar as novas conjunturas que marcam a esfera religiosa, incluindo as transformações no interior do mundo evangélico, sem perder de vista as características próprias - também em constante transformação - da esfera política em nossa sociedade.

Na primeira parte do livro, relacionada ao processo eleitoral de 2000 no Rio de Janeiro, Machado apresenta, em linhas gerais, as principais características dos candidatos e do eleitorado pentecostal neste município. Aponta para o crescimento numérico dos fiéis deste segmento evangélico e o aumento significativo de seu poder político nas últimas décadas, impulsionado, principalmente, por uma denominação em particular: a Igreja Universal do Reino de Deus. Em relação a este ator religioso, ganha destaque no texto o tripé política, mídia e assistência social que fundamenta seu projeto de ampliação da capacidade de influência na esfera pública brasileira. Outro aspecto interessante da atuação desta denominação é que o uso recorrente da lógica clientelista por parte de seus representantes políticos não se circunscreve apenas ao período eleitoral, mas se estende durante todo seu mandato e tem como público alvo majoritário o eleitorado feminino.

Ao mesmo tempo em que identifica o empreendimento da Iurd na esfera política como um marco no contexto atual, Machado atenta para o avanço significativo da Igreja Assembléia de Deus na política institucional, embora a atuação política de seus representantes seja mais recente e não se dê de forma tão organizada e centralizada como se observa na Iurd. Entre estas e outras denominações pentecostais e neopentecostais, a autora percebe uma pluralidade de percepções, comportamentos individuais e estratégias institucionais; contudo, observa que, de modo geral, "a intermediação da liderança religiosa se articula com a pouca informação e envolvimento político dos fiéis, facilitando a conquista dos votos dos membros das denominações religiosas", e que o "lançamento de candidaturas tem sido um recurso recorrente para a transferência da influência religiosa para a esfera política"(:31). Nesse sentido, a recorrência de um discurso que apela aos princípios éticos e morais para valorizar o pertencimento religioso, 
aliado a uma postura de denúncia ao oportunismo e à corrupção, é um aspecto que marca candidaturas e mandatos dos políticos pentecostais. A utilização do cargo eclesiástico como recurso para a garantia dos votos se apresentaria, por sua vez, como estratégia que cumpre um duplo papel: "sinalizaria que o candidato compartilha do ethos e da visão de mundo do grupo evangélico para o qual a campanha foi dirigida, mas também destacaria a autoridade do especialista do sagrado"(:35).

Aliado à estratégia de utilização do cargo eclesiástico, o corporativismo que caracteriza a relação entre os políticos evangélicos e suas respectivas denominações, e se estende, relativamente, à comunidade evangélica de modo geral, é um elemento fundamental na análise do caráter fluido da relação entre religião e política no país, pois revela uma conjunção de interesses diversos, interesses pessoais - dos políticos em relação à sua carreira, aos seus ideais e projetos e dos eleitores em relação, igualmente, aos seus ideais, projetos e necessidades - e interesses institucionais dos partidos em relação à sua orientação política, sua busca por projeção, suas estratégias para a formação de alianças etc., bem como das igrejas em relação a estes mesmos pontos e, em última instância, em relação à projeção também no campo religioso. Machado investe com rigor e brilhantismo no detalhamento deste quadro complexo, no entrelaçamento deste conjunto de interesses e no jogo de forças que ele envolve, apresentando, na segunda parte do livro, uma reflexão mais detida sobre o contexto político das eleições em 2002 e as atuações dos políticos eleitos ligados ao universo evangélico.

Nesta parte, Machado analisa as políticas assistencialistas e corporativistas que envolvem a atuação dos evangélicos na esfera pública, discutindo desde a rede montada no governo Garotinho em torno da distribuição do Cheque Cidadão e sua relação estreita com as igrejas evangélicas do município do Rio, até as campanhas eleitorais dos senadores evangélicos Manoel Ferreira, Liliam Sá e Marcelo Crivella. Entre os temas abordados pela autora nos capítulos seguintes estão: os efeitos do fortalecimento da capacidade de influência dos evangélicos na esfera pública, exemplificados pela eleição de Rosinha Matheus para o executivo do estado, uma mulher sem histórico expressivo no universo da política, mas com uma imagem pública fortalecida pela figura do marido e, principalmente, pela estrutura assistencialista que se propôs a consolidar; o deslocamento de alguns segmentos dessa tradição religiosa em direção à esquerda, expresso na importância da aliança entre segmentos evangélicos e forças de esquerda no país para a eleição de Lula à presidência em 2002; as diversas reações à forte presença dos evangélicos no cenário político estadual, pois, se por um lado, no contexto político de 2002 despontava uma inédita aliança entre evangélicos e oposição no nível federal, no nível partidário regional ainda permanecia a habitual discrepância entre políticos evangélicos e políticos de esquerda; as negociações dos diferentes atores políticos e estruturas eclesiásticas, retomando a discussão sobre o caráter fluido da relação entre religião e política expresso na atuação 
corporativista dos políticos evangélicos junto às suas respectivas denominações e ao universo evangélico de modo geral.

Outro aspecto fundamental desse "modelo" de atuação política evangélica na esfera pública abordado pela autora diz respeito à presença majoritária dos políticos evangélicos no poder Legislativo, que se explica não só pelo interesse destes sujeitos em defender a liberdade religiosa mas, principalmente, em "estender sua capacidade de regulação e controle aos indivíduos não pertencentes ao seu grupo confessional"(:116). Percebe-se que, além do corporativismo presente nos projetos de lei apresentados pelos políticos evangélicos analisados durante seu mandato, está explícita uma proposta de atuação que investe na moralização da população. E, nesse sentido, ao político evangélico não interessa apenas atender sua "clientela", mas também incorporar o papel de representante de uma visão de mundo que preza pelo bem e deseja construir o bem comum. Mais ainda, o político evangélico se apresenta como representante "do bem" para o interior de seu grupo e para os "de fora", que não partilham de sua visão de mundo, sendo, dessa forma, sua representatividade encarada como legítima por eleitores dos mais diversos setores da sociedade.

A imagem pública que esses sujeitos políticos constroem - não sem o apoio decisivo da estrutura eclesiástica que os envolve e de sua comunidade confessional - se fundamenta em alguns elementos centrais: o cargo eclesiástico, que já mencionei, o partido, com o apoio institucional que oferece e, em alguns casos, com o suporte ideológico que propicia, e os vínculos familiares e comunitários. Vale ressaltar que, de modo geral, não há uma relação estreita entre as propostas desses políticos e as propostas de seu partido, como a autora deixa claro em sua análise. Da mesma forma, a configuração do partido ao qual pertence o político, sua orientação ideológica e seu histórico na política nacional não são pontos decisivos para a escolha dos candidatos evangélicos por parte daqueles que os elegeram, fossem estes evangélicos ou não. Um dos indicadores deste quadro é a circulação intensa desses políticos por partidos diversos durante seu mandato: ainda que esta tenha se dado quase exclusivamente entre partidos de direita, revela uma marcante inconsistência na filiação partidária desses sujeitos. Nesta lógica, apresentar a feminilidade como atributo pode garantir ao sujeito político uma imagem associada ao "bem", ao serviço e à família. A utilização de candidatas evangélicas pelos partidos adquire também esse sentido, como evidencia Machado, mas envolve uma infinidade de outras nuances, que a autora apresenta com maestria e que apontarei, de modo breve e sucinto, para então encerrar este texto.

No que diz respeito à participação feminina na política evangélica, Machado volta sua atenção para a análise das candidatas que disputaram um cargo no Executivo do estado em 2002, Rosinha Matheus e Benedita da Silva, em suas estratégias na disputa por votos, bem com para a candidatura das mulheres evangélicas eleitas para o Legislativo regional e nacional em 2000. Seu interesse é "verificar 
como as mulheres que integram comunidades religiosas conhecidas pela distribuição assimétrica do poder justificam seu engajamento nas instituições políticas marcadamente masculinas, e exercem os cargos para os quais foram eleitas"(:123). Para isso, a autora busca examinar a relação dessas evangélicas tanto com os dirigentes de suas comunidades religiosas, quanto de suas agremiações partidárias. A utilização de mulheres nessas candidaturas, embora tenha adquirido um caráter estratégico para as agremiações e igrejas que as subsidiaram, não necessariamente já o tinha em sua origem e, nesse ponto, Machado é perspicaz ao ressaltar que estão em jogo tanto interesses meramente instrumentais - como a necessidade de preencher a cota de participação feminina no partido exigida legalmente - quanto a defesa de posições ideológicas. Sua hipótese central, neste momento, é de que a valorização das características "propriamente" femininas na promoção dessas candidatas sinaliza para a proposta de uma nova forma de fazer política, que se desvincula do caráter tradicionalmente masculino e emerge com novos matizes. E, ao partir desse ponto, a autora consegue produzir uma análise refinada que, mais uma vez, opera no interior de um quadro complexo de percepções, interesses e estratégias.

A meu ver, e com isso encerro este texto, a proposta de um olhar que entende o assistencialismo e o corporativismo na política evangélica como recursos eleitorais, de um lado, e como expressão de seu ethos religioso associado à atividade política, de outro, é um empreendimento metodológico que enfrenta a fundo o desafio de compreender a forma pela qual o religioso e o político se entrelaçam nas ações dos sujeitos, sem ingenuidades, e que contribui efetivamente e valiosamente com as interlocuções no interior desse campo de análise. E vale aqui acrescentar que a riqueza dos dados expostos, de modo claro e consistente, torna esta uma leitura muito interessante, além de imprescindível.

\section{Referências Bibliográficas}

CASANOVA, José. (1999), "Religiones públicas e privadas". In: J. Auyero. Cája de herramientas. Buenos Aires: s.ed.

GUIMBELli, Emerson. (2002), O fim da Religião. São Paulo: Attar.

MONTERO, Paula. (2002), "Secularización". In: B. Sarlo et al. Termos Críticos de sociologia de la cultura. Buenos Aires: Paidós.

Suene dos Santos de Almeida (suenesalmeida@ig.com.br) Aluna do Programa de Pós-Graduação em Ciências Sociais, UERJ. 